\title{
Metabolic Health, Obesity, and the Risk of Developing Open-Angle Glaucoma: Metabolically Healthy Obese Patients versus Metabolically Unhealthy but Normal Weight Patients
}

\author{
Younhea Jung ${ }^{1}$, Kyungdo Han², Hae-Young L. Park³ , Seung Hoon Lee ${ }^{1}$, Chan Kee Park ${ }^{3}$ \\ ${ }^{1}$ Department of Ophthalmology, Yeouido St. Mary’s Hospital, College of Medicine, The Catholic University of Korea, Seoul, \\ ${ }^{2}$ Department of Biostatistics, College of Medicine, The Catholic University of Korea, Seoul, \\ ${ }^{3}$ Department of Ophthalmology, Seoul St. Mary's Hospital, College of Medicine, The Catholic University of Korea, Seoul, Korea
}

Background: This study sought to investigate the associations between metabolic health status, obesity, and incidence of primary open-angle glaucoma (POAG).

Methods: In this nationwide, population-based, longitudinal prospective cohort study conducted using the Korean National Health Insurance System, we categorized all subjects based on presence and severity of metabolic syndrome and obesity. Insurance claims data were used to identify POAG development. Then, Cox regression was applied to calculate the hazard of developing POAG in people with various components of metabolic syndrome, obesity, or their combination.

Results: Of the total 287,553 subjects, 4,970 (1.3\%) developed POAG. High fasting glucose, blood pressure, and total cholesterol levels were all associated with increased risk of developing POAG. Regarding obesity level, people with body mass index (BMI) greater than $30 \mathrm{~kg} / \mathrm{m}^{2}$ were more likely to develop POAG than those with normal BMI. Also, people with greater number of metabolic syndrome components showed a greater POAG incidence. People who are metabolically unhealthy and obese (adjusted hazard ratio [HR], 1.574; 95\% confidence interval [CI], 1.449 to 1.711 ) and those who are metabolically unhealthy nonobese (MUNO: adjusted HR, 1.521; 95\% CI, 1.405 to 1.645) but not those who are metabolically healthy obese (MHO: adjusted HR, 1.019; $95 \%$ CI, 0.907 to 1.144 ) had an increased hazard of developing POAG compared with metabolically healthy nonobese (MHNO) subjects.

Conclusion: Metabolic health status and obesity were significantly associated with increased risk of POAG incidence. MUNO subjects but not MHO subjects showed a higher risk of POAG development than did MHNO subjects, suggesting that metabolic status is more important than obesity in POAG.

Keywords: Diabetes mellitus; Glaucoma, open-angle; Hypercholesterolemia; Hypertension; Metabolic syndrome; Obesity

\section{INTRODUCTION}

Glaucoma is characterized by irreversible damage to the optic nerve, which can cause blindness, and is the leading cause of irreversible blindness worldwide. Globally, 64.3 million people were estimated to have glaucoma in 2013, with the number expected to increase to 111.8 million in 2040 [1]. Although irreversible, its progression can be delayed by treatment; therefore, identifying risk factors associated with the disease to promote earlier detection is important.
Corresponding author: Chan Kee Park (iD https://orcid.org/0000-0002-0922-8293 Department of Ophthalmology, Seoul St. Mary's Hospital, College of Medicine, The Catholic University of Korea, 222 Banpo-daero, Seocho-gu, Seoul 06591, Korea E-mail: ckpark@catholic.ac.kr

Received: Mar. 14, 2019; Accepted: May 17, 2019
This is an Open Access article distributed under the terms of the Creative Commons Attribution Non-Commercial License (https://creativecommons.org/licenses/by-nc/4.0/) which permits unrestricted non-commercial use, distribution, and reproduction in any medium, provided the original work is properly cited. 
Many risk factors for glaucoma development have been recognized including increased intraocular pressure (IOP) [2], family history of glaucoma [3], age [4], and African ancestry [5]. In addition, hemodynamic factors have been identified to play an important role in the pathogenesis of primary openangle glaucoma (POAG); thus, metabolic health status and obesity may affect POAG development [6,7]. However, metabolic health status and obesity have been shown to have conflicting relationships with glaucoma [6,8-14]. This inconsistency could be attributed to differences in the characteristics of the study population, dissimilar definitions or categories of diseases, or variation in follow-up periods. It may also be due to interactions between metabolic health and obesity. It has been suggested that, despite similarities in obesity level, which is most frequently measured by body mass index (BMI), individuals show different clinical outcomes depending on metabolic statuses $[15,16]$. Individuals who are obese but metabolically healthy show lower degrees of insulin resistance, visceral adiposity, and cardiovascular risk. Conversely, individuals who are nonobese but metabolically unhealthy show higher degrees of insulin resistance, visceral adiposity, blood pressure (BP), oxidative stress, and cardiovascular mortality [16-19].

To the best of our knowledge, the risk of POAG development has not been previously compared in the context of combinations of metabolic status and obesity. Therefore, in this study, we assessed the effects of metabolic status and obesity, both presence and severity, on development of POAG using a nationwide longitudinal sample of individuals enrolled from throughout South Korea. Furthermore, we sought to understand how different combinations of metabolic status and obesity affected the likelihood of developing POAG after adjusting for potentially confounding factors.

\section{METHODS}

\section{Database}

The Korean National Health Insurance System (KNHIS) requires that all South Koreans enroll in the system and contains comprehensive health-related information for all nationals. With this system, medical providers receive $30 \%$ of total medical expenses from patients themselves and the other $70 \%$ from the KNHIS, for which they must submit claims [20]. In addition, the KNHIS offers free general health checkups to all insured Koreans and their dependents over the age of 40 years, at least biennially. The KNHIS contains data regarding personal information about the patient (an unidentifiable code representing each individual as well as age, sex, socioeconomic variables, area of residency, and household income level), medical treatment based on medical claims made by medical providers (diagnostic codes, treatment procedures, prescription drugs, information about the hospital, total medical costs), and the results of general health examination. A customized database of $1,025,340$ subjects $(2.2 \%)$ was compiled from the entire Korean population in $2002(46,605,433$ subjects) by stratified random sampling to represent the total population, and the subjects were tracked until 2013.

The KNHIS national sample cohort 2002 to 2013 (KNHISNSC 2002 to 2013) project was approved by the Institutional Review Board of the KNHIS. This study followed the tenets of the Declaration of Helsinki and was approved by the Institutional Review Board of Seoul St. Mary's Hospital (KC15EISI0294). Written informed consent by the patients was waived due to a retrospective nature of our study.

\section{Participants}

From the KNHIS-NSC 2002 to 2013 project, we included subjects who had undergone a general health examination at least once between 2002 and $2008(n=424,712)$. Subjects were identified as having POAG if they had at least two visits for POAG (International Classification of Diseases [ICD]-10 code H40.1) and received antiglaucoma medications during the study period. We excluded subjects aged younger than 40 years $(n=$ 136,834 ) and those who were diagnosed with POAG prior to enrollment $(n=325)$ to exclude nonincident cases. Ultimately, the study included 287,553 subjects. If a subject underwent more than one health examination, the results from their first health examination were included in the analysis.

\section{Measurements and demographic factors}

Health examinations were performed in hospitals that were certified by the KNHIS. Anthropometric measurements were performed with the subjects wearing light clothing. BMI was calculated as subject weight in kilograms divided by the square of subject height in meters. BP was measured in a seated position after an at least 5-minute rest. Blood samples for glucose serum and total cholesterol (TC) levels were collected following overnight fasting. Data on history of smoking (no, past, or current), alcohol consumption (no, less than two to three times/ month, once or more/week), and exercise (no activity, less than four times/week, or five times or more/week) were obtained 
using a questionnaire. Subject medication history was gathered based on clinic and pharmacy ICD-10 codes, list of prescribed medications, and medical history obtained via a questionnaire. Subject socioeconomic status was dichotomized into lower $20 \%$ and upper $80 \%$ groups based on household income. Area of residency was categorized as either urban or rural.

\section{Definitions of metabolically healthy obesity}

Metabolically healthy patients were defined as those who were free of metabolic syndrome components. If a subject had at least one of diabetes mellitus (DM), hypertension, and hypercholesterolemia, the participant was considered to be metabolically unhealthy. DM was defined based on ICD-10 codes (E11-E14) and prescription of antidiabetic medications or a fasting plasma glucose (FPG) $\geq 126 \mathrm{mg} / \mathrm{dL}$. Hypertension was defined based on ICD-10 codes (I10, I11, I12, I13, and I15) and prescription of antihypertensive medications, a systolic $\mathrm{BP}$ $(\mathrm{SBP}) \geq 140 \mathrm{~mm} \mathrm{Hg}$, or a diastolic BP (DBP) $\geq 90 \mathrm{~mm} \mathrm{Hg}$. Prehypertension was defined as a SBP from 120 to $139 \mathrm{~mm} \mathrm{Hg}$ or a DBP from 80 to $89 \mathrm{~mm} \mathrm{Hg}$. Hypercholesterolemia was defined based on an ICD-10 code (E78) and prescription of cholesterol medications or TC $\geq 240 \mathrm{mg} / \mathrm{dL}$. Obesity was defined as BMI $\geq 25 \mathrm{~kg} / \mathrm{m}^{2}$.

Subjects were categorized into the following four groups based on metabolic status and obesity: metabolically healthy nonobese (MHNO), metabolically unhealthy nonobese (MUNO), metabolically healthy obese (MHO), and metabolically unhealthy obese (MUO).

\section{Statistical analyses}

Student $t$-test was used to compare continuous variables, and chi-square test was used to compare categorical variables. The duration of follow-up (person-years) was calculated from the enrollment date (2002 to 2008) to the date of POAG diagnosis or to the end of follow-up (December 2013). Cox proportional hazards analysis was performed to estimate the overall hazard ratio (HR) and 95\% confidence interval (CI) for the associations of DM, hypertension, hypercholesterolemia, and BMI with POAG development. To identify the graded risk of POAG development by level of metabolic syndrome component, DM, hypertension, hypercholesterolemia, and obesity were each stratified into subgroups based on levels of FPG (FPG $<100$, $100 \leq \mathrm{FPG}<126,126 \mathrm{mg} / \mathrm{dL} \leq \mathrm{FPG}$, or on medication); SBP or DBP (SBP $<120$ or DBP $<80,120 \leq \mathrm{SBP}<140$ or $80 \leq \mathrm{DBP}$ $<90$, SBP $\geq 140$ or DBP $\geq 90 \mathrm{mmHg}$, or on medication); TC
(TC $<200,200 \leq$ TC $<240,240 \mathrm{mg} / \mathrm{dL} \leq \mathrm{TC}$, or on medication); and BMI ( $<18.5,18.5$ to $22.9,23$ to $24.9,25$ to 29.9 , and $\left.\geq 30 \mathrm{~kg} / \mathrm{m}^{2}\right)$, respectively.

In addition, we calculated the HR of incident POAG according to number of metabolic syndrome components. We also calculated the HR of each metabolic syndrome component and obesity level for new-onset POAG, stratified by sex and age ( $<64$ years vs. $\geq 65$ years). The Kaplan-Meier curve was used to calculate the overall disease-free rate, while the log-rank test was performed to investigate the differences in the effect of metabolic state and obesity on POAG development. Furthermore, we examined the association between groups stratified according to metabolic status and obesity and POAG incidence. Multivariable HRs were calculated after adjusting for age, sex, smoking, exercise, and income. A $P$ value less than 0.05 was considered significant. All statistical analyses were performed using SAS version 9.3 (SAS Institute Inc., Cary, NC, USA).

\section{RESULTS}

Of the 287,553 participants who were included in the present analysis, 4,970 (1.73\%) developed POAG. Baseline characteristics of participants with and without incident POAG are shown in Table 1. Participants who developed POAG were more likely to be older than 65 years and male. These individuals additionally showed higher BMI, SBP, DBP, serum glucose, and TC levels than did those without POAG.

\section{Association with open-angle glaucoma: components of metabolic syndrome and BMI}

Table 2 shows the HR for POAG according to DM, hypertension, and hypercholesterolemia parameters as well as obesity levels and number of metabolic syndrome components. People with higher FPG level had a higher risk of developing POAG ([HR, 1.21; 95\% CI, 1.13 to 1.29 ] and [HR, 1.54; 95\% CI, 1.36 to 1.74 ] for $100 \leq$ FPG $<126$ and FPG $\geq 126 \mathrm{mg} / \mathrm{dL}$, respectively). People with prior diagnosis of DM who were under medication also had increased risk of developing POAG (HR, 3.26; 95\% CI, 3.01 to 3.53). Separately, people with higher SBP or DBP were more likely to develop POAG ([HR, 1.23; 95\% CI, 1.13 to 1.34 ] and [HR, 1.68 ; $95 \%$ CI, 1.53 to 1.84 ] for $120 \leq$ SBP $<140$ or $80 \leq \mathrm{DBP}<90$ and $\mathrm{SBP} \geq 140$ or DBP $\geq 90 \mathrm{~mm} \mathrm{Hg}$, respectively). Those with prior diagnosis of hypertension who are on medication were also more likely to develop POAG (HR, 2.83; 95\% CI, 2.61 to 3.08). People with higher cholesterol lev- 
Table 1. Comparison of baseline characteristics between subjects with and without glaucoma

\begin{tabular}{|c|c|c|c|}
\hline \multirow[b]{2}{*}{ Characteristic } & \multicolumn{3}{|c|}{ Development of glaucoma } \\
\hline & $\begin{array}{c}\text { Yes } \\
(n=4,970)\end{array}$ & $\begin{array}{c}\text { No } \\
(n=282,583)\end{array}$ & $P$ value \\
\hline Age $\geq 65 \mathrm{yr}$ & $1,687(33.94)$ & $44,790(15.85)$ & $<0.001$ \\
\hline Male sex & $2,603(52.37)$ & $138,576(49.04)$ & $<0.001$ \\
\hline Height, cm & $160.4 \pm 9.1$ & $161.2 \pm 8.9$ & $<0.001$ \\
\hline Weight, kg & $62.3 \pm 10.6$ & $62.3 \pm 10.5$ & 0.882 \\
\hline $\mathrm{BMI}, \mathrm{kg} / \mathrm{m}^{2}$ & $24.1 \pm 3.1$ & $23.9 \pm 3.1$ & $<0.001$ \\
\hline SBP, mm Hg & $130.4 \pm 18.3$ & $126.1 \pm 17.8$ & $<0.001$ \\
\hline DBP, $\mathrm{mm} \mathrm{Hg}$ & $80.3 \pm 11.5$ & $78.6 \pm 11.5$ & $<0.001$ \\
\hline $\begin{array}{l}\text { Fasting plasma glucose, } \\
\text { mg/dL }\end{array}$ & $107.1 \pm 43.3$ & $98.5 \pm 31.3$ & $<0.001$ \\
\hline Total cholesterol, mg/dL & $202.3 \pm 39.5$ & $198.5 \pm 38.2$ & $<0.001$ \\
\hline Smoking & & & $<0.001$ \\
\hline No & $3,363(74.82)$ & $185,671(72.18)$ & \\
\hline Past & $216(4.81)$ & $11,817(4.59)$ & \\
\hline Current & $916(20.38)$ & $59,761(23.23)$ & \\
\hline Alcohol & & & $<0.001$ \\
\hline No & $3,021(62.46)$ & $159,001(58.58)$ & \\
\hline$<2-3$ times $/$ mo & $608(12.57)$ & $38,628(14.23)$ & \\
\hline$\geq$ once/wk & $1,208(24.97)$ & $73,788(27.19)$ & \\
\hline Exercise & & & $<0.001$ \\
\hline No & $2,682(55.38)$ & $154,422(56.21)$ & \\
\hline$\leq 4$ times/wk & $1,511(31.20)$ & $93,662(34.09)$ & \\
\hline$\geq 5$ times/wk & $650(13.42)$ & $26,635(9.70)$ & \\
\hline Diabetes mellitus, mg/dL & & & $<0.001$ \\
\hline Glucose $<100$ & $2,750(55.38)$ & $188,299(66.70)$ & \\
\hline $100 \leq$ glucose $<126$ & $1,152(23.20)$ & $65,349(23.15)$ & \\
\hline $126 \leq$ glucose & $280(5.64)$ & $12,431(4.40)$ & \\
\hline $\begin{array}{l}\text { Prior diagnosis (under } \\
\text { medication) }\end{array}$ & $784(15.79)$ & $16,224(5.75)$ & \\
\hline
\end{tabular}

(Continued to the next)

els showed increased risk of developing POAG ([HR, 1.09; 95\% CI, 1.02 to 1.16 ] and [HR, 1.30; 95\% CI, 1.19 to 1.41 ] for $200 \leq$ TC $<240$ and $240 \mathrm{mg} / \mathrm{dL} \leq \mathrm{TC}$, respectively). People with prior diagnosis of hypercholesterolemia on medication showed a higher risk of developing POAG (HR, 2.14; 95\% CI, 1.95 to 2.35), and people with a greater number of metabolic syndrome components were more likely to develop POAG ([HR, 1.77; 95\% CI, 1.66 to 1.89 ], [HR, 2.74; 95\% CI, 2.54 to 2.96], and [HR, 4.17; 95\% CI, 3.68 to 4.72 ] for one, two, and
Table 1. Continued

\begin{tabular}{|c|c|c|c|}
\hline \multirow[b]{2}{*}{ Characteristic } & \multicolumn{3}{|c|}{ Development of glaucoma } \\
\hline & $\begin{array}{c}\text { Yes } \\
(n=4,970)\end{array}$ & $\begin{array}{c}\text { No } \\
(n=282,583)\end{array}$ & $P$ value \\
\hline Hypertension & & & $<0.001$ \\
\hline No & $874(17.59)$ & $76,378(27.04)$ & \\
\hline Prehypertension & $1,459(29.37)$ & $103,312(36.57)$ & \\
\hline Newly diagnosed & $1,055(21.24)$ & $54,568(19.32)$ & \\
\hline $\begin{array}{l}\text { Prior diagnosis (under } \\
\text { medication) }\end{array}$ & $1,580(31.80)$ & $48,232(17.07)$ & \\
\hline $\begin{array}{l}\text { Hypercholesterolemia, } \\
\mathrm{mg} / \mathrm{dL}\end{array}$ & & & $<0.001$ \\
\hline Total cholesterol $<200$ & 2,274 (45.83) & $146,157(51.80)$ & \\
\hline $\begin{array}{l}200 \leq \text { total cholesterol } \\
<240\end{array}$ & $1,469(29.60)$ & $86,871(30.79)$ & \\
\hline $240 \leq$ total cholesterol & $652(13.14)$ & $32,214(11.42)$ & \\
\hline $\begin{array}{l}\text { Prior diagnosis (under } \\
\text { medication) }\end{array}$ & $567(11.43)$ & $16,893(5.99)$ & \\
\hline BMI level, kg/m² & & & $<0.001$ \\
\hline$<18.5$ & $129(2.60)$ & $7,341(2.60)$ & \\
\hline$\geq 18.5$ and $<23$ & $1,694(34.08)$ & $103,958(36.79)$ & \\
\hline$\geq 23$ and $<25$ & $1,331(26.78)$ & $74,764(26.46)$ & \\
\hline$\geq 25$ and $<30$ & $1,624(32.68)$ & $87,769(31.06)$ & \\
\hline$\geq 30$ & $192(3.86)$ & $8,751(3.10)$ & \\
\hline Income (low 20\%) & 744 (14.97) & $44,493(15.75)$ & 0.137 \\
\hline Residential area (rural) & $2,738(55.09)$ & $154,896(54.81)$ & 0.698 \\
\hline
\end{tabular}

Values are presented as number (\%) or mean \pm standard deviation. BMI, body mass index; SBP, systolic blood pressure; DBP, diastolic blood pressure.

three risk factors, respectively).

Regarding obesity, people with BMI of $30 \mathrm{~kg} / \mathrm{m}^{2}$ or greater were more likely to develop POAG than those with BMI between 18.5 and $22.9 \mathrm{~kg} / \mathrm{m}^{2}$, in a statistically significant manner (HR, 1.35 ; $95 \%$ CI, 1.16 to 1.56 ).

Furthermore, after stratifying by age, those younger than 65 years showed a relatively higher risk of developing POAG at higher levels of FPG, BP, cholesterol, and BMI and with greater number of metabolic syndrome components (Table 3). In comparison, those who were 65 years old or older showed relatively weaker relationships; those with prior diagnosis of DM, hypertension, or hypercholesterolemia under medication showed greater risk of developing POAG, but the levels of FPG, BP, cholesterol, and BMI did not lead to a statistically sig- 
Table 2. Association between metabolic parameters and the development of primary open-angle glaucoma

\begin{tabular}{|c|c|c|c|c|c|c|}
\hline \multirow{2}{*}{ Variable } & \multirow{2}{*}{ Cases } & \multirow{2}{*}{ Person-years } & \multirow{2}{*}{ Incidence rate ${ }^{\mathrm{a}}$} & \multirow{2}{*}{ HR } & \multicolumn{2}{|c|}{$95 \% \mathrm{CI}$} \\
\hline & & & & & Lower & Upper \\
\hline \multicolumn{7}{|l|}{ Diabetes mellitus, mg/dL } \\
\hline FPG $<100$ & 2,750 & $2,258,482$ & 1.22 & 1.00 & & \\
\hline $100 \leq \mathrm{FPG}<126$ & 1,152 & 784,899 & 1.47 & 1.21 & 1.13 & 1.29 \\
\hline $126 \leq \mathrm{FPG}$ & 280 & 149,754 & 1.87 & 1.54 & 1.36 & 1.74 \\
\hline Under medication & 784 & 197,495 & 3.97 & 3.26 & 3.01 & 3.53 \\
\hline \multicolumn{7}{|l|}{ Hypertension, mm Hg } \\
\hline $\mathrm{SBP}<120$ and $\mathrm{DBP}<80$ & 874 & 913,715 & 0.96 & 1.00 & & \\
\hline $120 \leq \mathrm{SBP}<140$ or $80 \leq \mathrm{DBP}<90$ & 1,459 & $1,238,740$ & 1.18 & 1.23 & 1.13 & 1.34 \\
\hline $\mathrm{SBP} \geq 140$ or $\mathrm{DBP} \geq 90$ & 1,055 & 657,051 & 1.61 & 1.68 & 1.53 & 1.84 \\
\hline Under medication & 1,580 & 583,359 & 2.71 & 2.83 & 2.61 & 3.08 \\
\hline \multicolumn{7}{|l|}{ Hypercholesterolemia, mg/dL } \\
\hline $\mathrm{TC}<200$ & 2,274 & $1,753,651$ & 1.30 & 1.00 & & \\
\hline $200 \leq \mathrm{TC}<240$ & 1,469 & $1,043,186$ & 1.41 & 1.09 & 1.02 & 1.16 \\
\hline $240 \leq \mathrm{TC}$ & 652 & 387,708 & 1.68 & 1.30 & 1.19 & 1.41 \\
\hline Under medication & 567 & 204,060 & 2.78 & 2.14 & 1.95 & 2.35 \\
\hline \multicolumn{7}{|c|}{ No. of metabolic syndrome components } \\
\hline 0 & 1,678 & $1,760,393$ & 0.95 & 1.00 & & \\
\hline 1 & 1,957 & $1,161,052$ & 1.69 & 1.77 & 1.66 & 1.89 \\
\hline 2 & 1,044 & 399,266 & 2.61 & 2.74 & 2.54 & 2.96 \\
\hline 3 & 291 & 73,280 & 3.97 & 4.17 & 3.68 & 4.72 \\
\hline \multicolumn{7}{|l|}{ Body mass index, $\mathrm{kg} / \mathrm{m}^{2}$} \\
\hline$<18.5$ & 129 & 88,260 & 1.46 & 1.08 & 0.90 & 1.29 \\
\hline $18.5-22.9$ & 1,694 & $1,247,517$ & 1.36 & 1.00 & & \\
\hline $23-24.9$ & 1,331 & 898,068 & 1.48 & 1.09 & 1.02 & 1.17 \\
\hline $25-29.9$ & 1,624 & $1,054,854$ & 1.54 & 1.13 & 1.06 & 1.21 \\
\hline$\geq 30$ & 192 & 105,294 & 1.82 & 1.35 & 1.16 & 1.56 \\
\hline
\end{tabular}

HR, hazard ratio; CI, confidence interval; FPG, fasting plasma glucose; SBP, systolic blood pressure; DBP, diastolic blood pressure; TC, total cholesterol.

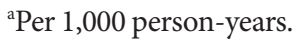

nificant difference regarding the hazard of developing POAG. Separately, those aged 65 years or older with a greater number of metabolic syndrome components showed a greater risk of incident POAG. Also, in terms of absolute risk increment, the incidence rates of developing POAG at higher levels of FPG, $\mathrm{BP}$, cholesterol, and BMI were higher in those younger than 65 years of age compared with those 65 years of age or older.

Moreover, when stratified by sex, both men and women exhibited significantly higher risks of developing POAG at higher levels of FPG, BP, and cholesterol and with greater number of metabolic syndrome components, but the HR was higher in women than in men (Table 4). Regarding BMI, higher BMI level increased the hazard of developing POAG only in women ([HR, 1.14; 95\% CI, 1.03 to 1.27], [HR, 1.25; 95\% CI, 1.13 to 1.38], and [HR, 1.61; $95 \% \mathrm{CI}, 1.33$ to 1.94] for BMI of 23 to $24.9,25$ to 29.9 , and $\geq 30 \mathrm{~kg} / \mathrm{m}^{2}$, respectively).

\section{Association with open-angle glaucoma: MHO individuals vs. MUNO individuals}

Table 5 shows HR values for developing POAG according to 


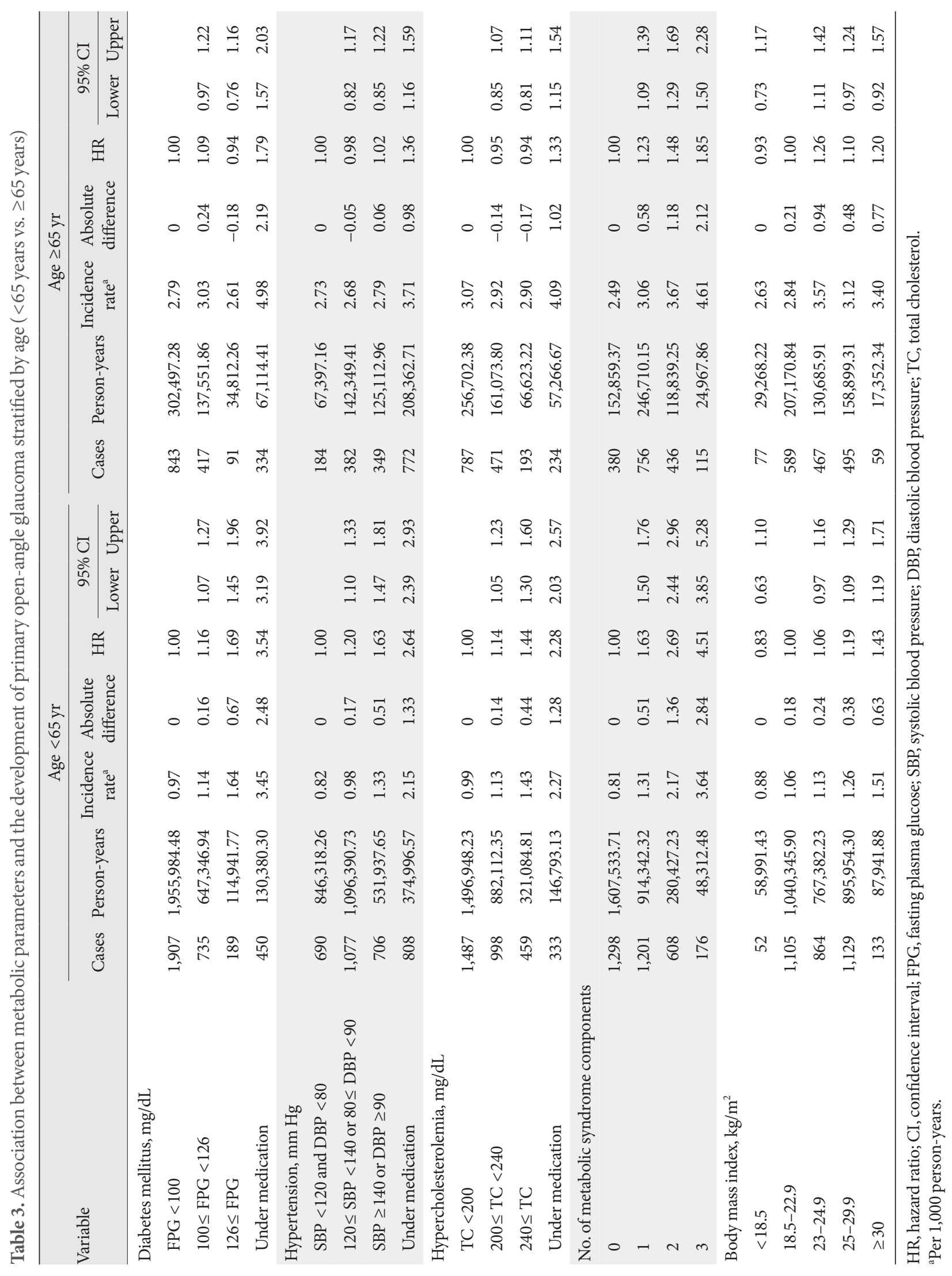




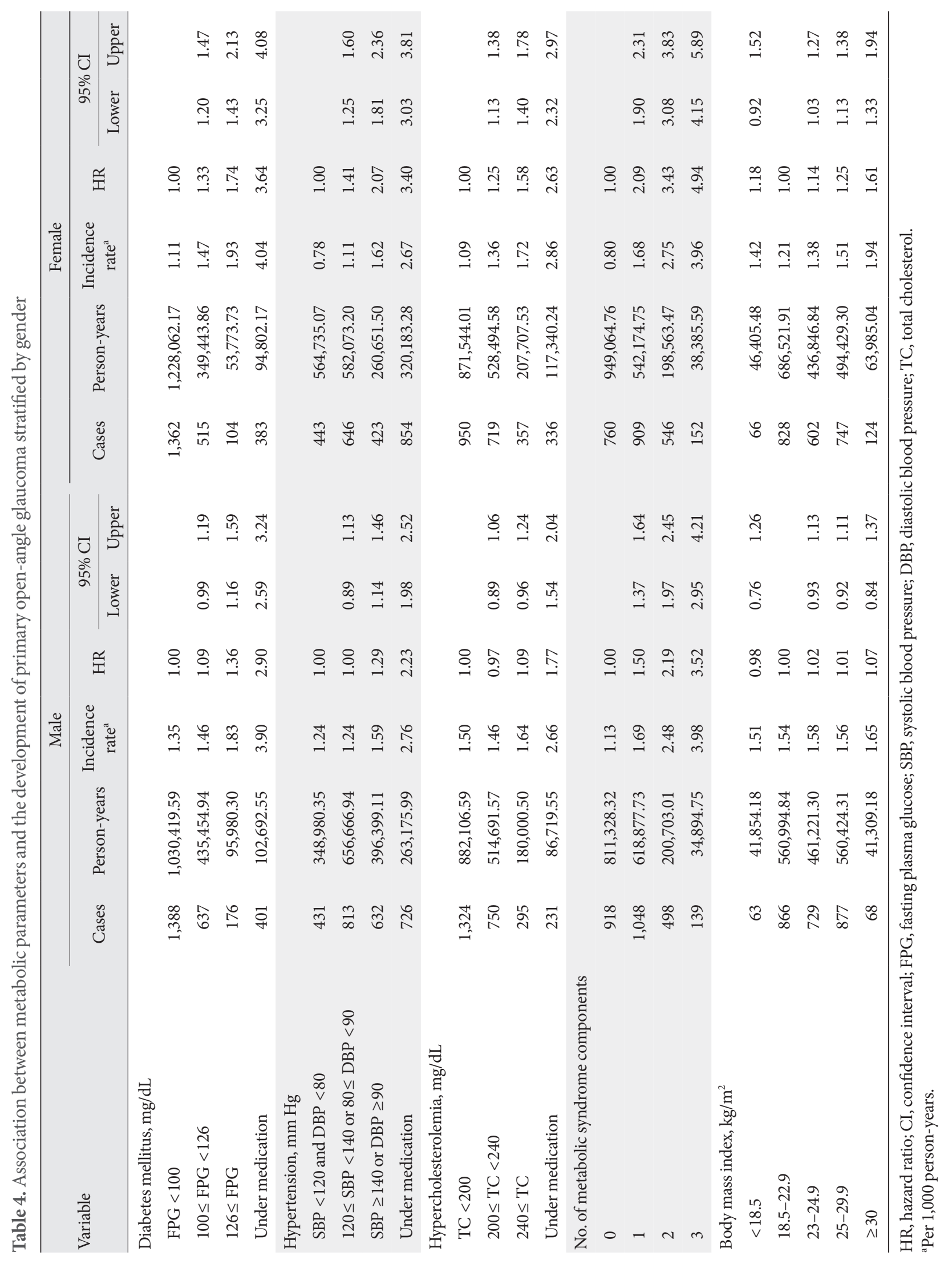


Table 5. Association between metabolic status and incident primary open-angle glaucoma

\begin{tabular}{|c|c|c|c|c|c|c|}
\hline & Cases & Person-years & Incidence rate $\mathrm{a}^{\mathrm{a}}$ & Model 1 & Model 2 & Model 3 \\
\hline MHNO & 1,233 & $1,306,444$ & 0.94 & 1 & 1 & 1 \\
\hline MUNO & 1,921 & 927,400 & 2.07 & $2.191(2.040-2.354)$ & $1.515(1.406-1.632)$ & $1.521(1.405-1.645)$ \\
\hline $\mathrm{MHO}$ & 445 & 453,949 & 0.98 & $1.038(0.931-1.157)$ & $1.052(0.944-1.173)$ & $1.019(0.907-1.144)$ \\
\hline MUO & 1,371 & 706,199 & 1.94 & $2.056(1.903-2.220)$ & $1.575(1.457-1.703)$ & $1.574(1.449-1.711)$ \\
\hline
\end{tabular}

Values are presented as hazard ratio (95\% confidence interval). Model 1: unadjusted; Model 2: adjusted for age, gender; Model 3: adjusted for age, gender, smoking, alcohol, exercise, income, and residential area.

MHNO, metabolically healthy nonobese; MUNO, metabolically unhealthy nonobese; MHO, metabolically health obese; MUO, metabolically unhealthy obese.

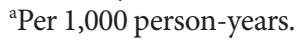
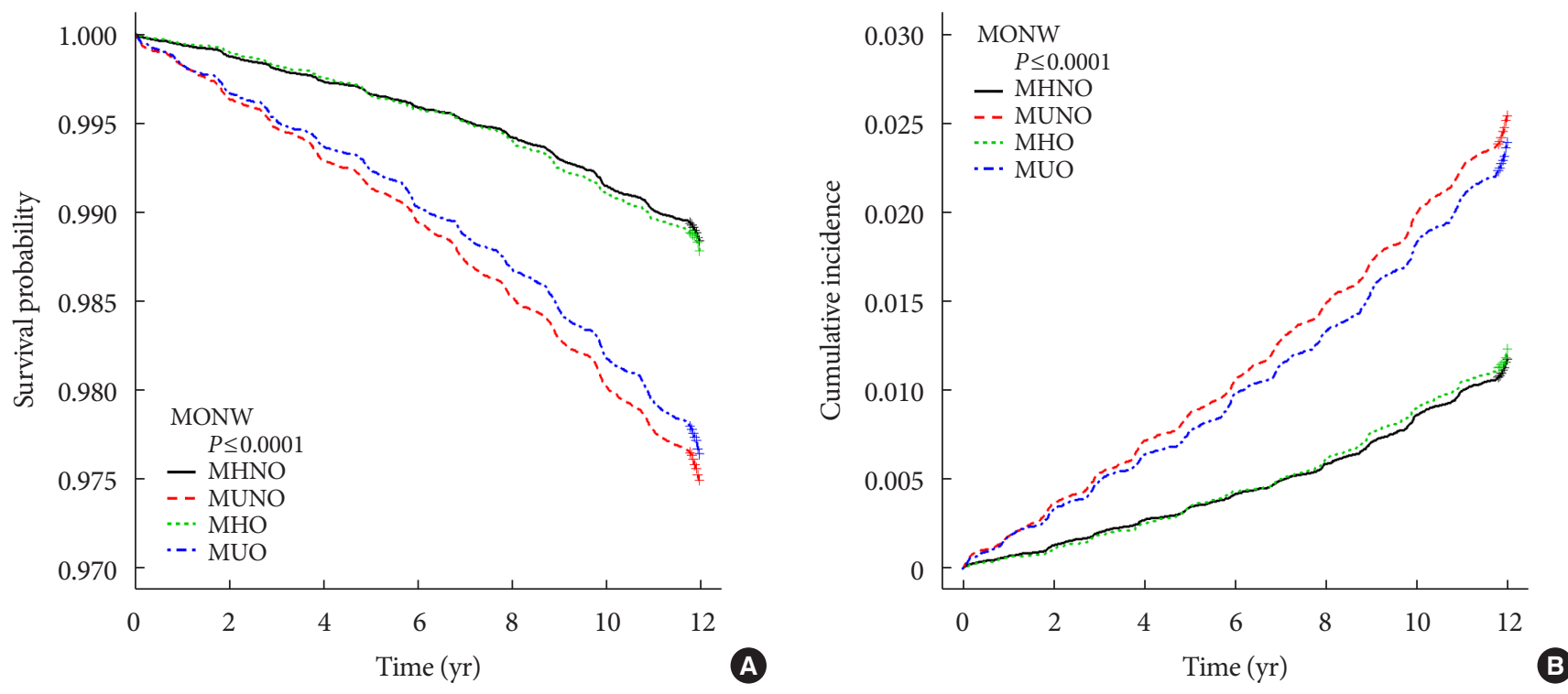

Fig. 1. Kaplan Meier survival analysis (A) and cumulative incidence (B) of primary open-angle glaucoma according to metabolic status and obesity. MHNO, metabolically healthy nonobese; MUNO, metabolically unhealthy nonobese; MHO, metabolically health obese; MUO, metabolically unhealthy obese.

metabolic syndrome component and obesity status with and without adjustment for confounding factors.

Compared with MHNO subjects, MUO individuals had an increased hazard of developing POAG before and after adjusting for age, sex, and sociodemographic confounding factors ([HR, 2.056; 95\% CI, 1.903 to 2.220] and [adjusted HR, 1.574; 95\% CI, 1.449 to 1.711]). MUNO individuals also showed a higher risk of developing POAG before and after adjusting for confounders ([HR, 2.191; 95\% CI, 2.040 to 2.354] and [adjusted HR, 1.521; 95\% CI, 1.405 to 1.645$]$ ), while MHO patients showed no significant difference in hazard of developing POAG before and after adjusting for covariates ([HR, 1.038; 95\% CI, 0.931 to 1.157] and [adjusted HR, 1.019; 95\% CI, 0.907 to 1.144$])$.

Fig. 1 shows Kaplan-Meier survival analysis for development of POAG according to metabolic status and obesity.

\section{DISCUSSION}

In this study, all components of metabolic syndrome including $\mathrm{DM}$, hypertension, and hypercholesterolemia individually increased the risk of developing POAG. Also, higher level of FPG, BP, and TC each increased the risk of POAG incidence. Furthermore, a greater number of metabolic syndrome components and higher level of FPG, BP, or cholesterol independently increased this risk. These trends were similarly observed 
among both sexes and across age groups.

Moreover, regarding different combinations of metabolic status and obesity, we observed that metabolic status was more important than obesity, as individuals who were MUNO or MUO showed higher risk of developing POAG in comparison with those who were MHNO, whereas those who were $\mathrm{MHO}$ did not. This relationship was significant both before and after adjusting for age, sex, and sociodemographic confounding factors.

Other studies have reported the association between metabolic syndrome and POAG development with various results. Newman-Casey et al. [6] found that DM (HR, 1.35; 95\% CI, 1.21 to 1.50 ) and hypertension (HR, 1.17; 95\% CI, 1.13 to 1.22 ) individually increased the risk of developing open-angle glaucoma using medical claims data from throughout the United States. However, in their study, hyperlipidemia decreased the risk of open-angle glaucoma (HR, 0.95; 95\% CI, 0.91 to 0.98 ). In another study by Imai et al. [8], high levels of FPG, BP, and triglycerides were each related with high IOP. Kim et al. [9] reported that hypertension and impaired glucose tolerance were related with increased risk of glaucoma. In a cross-sectional study performed using a nationwide database, the prevalence of glaucoma was statistically significantly higher in those with greater numbers of metabolic syndrome components [9]. In addition, in the same study, the prevalence values of hypertension, high FPG, and high triglycerides were higher in those with glaucoma than those without. Kim et al. [10] additionally reported a positive association between number of metabolic syndrome components and glaucoma.

There could be several possible reasons for increased risk of POAG development in patients with metabolic syndrome. First, metabolic syndrome may increase IOP. Participants with metabolic syndrome showed higher IOP than did those without, and those with greater number of metabolic syndrome components also had higher IOP $[8,21,22]$. It has been hypothesized that hypertension may increase IOP by promoting greater blood flow to the ciliary artery, which results in excessive aqueous humor production [23]. Also, DM may elevate IOP by increasing the osmotic gradient, which can draw more aqueous humor into the anterior chamber [21]. This can also cause fibronectin accumulation in the trabecular meshwork, interrupting the aqueous outflow facility [24].

However, metabolic syndrome is reported to be related with certain findings in even normal-tension glaucoma (NTG) [10]. In one study, metabolic syndrome was independently related with reduced retinal nerve fiber layer thickness, suggesting that metabolic syndrome may also be related with neurodegeneration in glaucoma [25]. The positive relationship between metabolic syndrome components and POAG in our investigation emphasized the possible relationship between metabolic syndrome and neurodegeneration in glaucoma, considering the greater prevalence of NTG in comparison with high-tension glaucoma in Koreans than in other ethnicities [26].

Kim et al. [10] reported in a cross-sectional study that hypertension and impaired glucose tolerance increased the risk of NTG, and a greater number of metabolic syndrome components was positively related with NTG. Hypertension may cause arteriolosclerotic damage, while DM also causes damage to small blood vessels, which can reduce blood flow to the optic nerve head and promote endothelial cell dysfunction; this affects vascular autoregulation, increasing vulnerability to glaucomatous neurodegeneration [27,28]. Hypercholesterolemia is an important risk factor for atherosclerosis [29] and may also reduce blood flow to the optic nerve head, resulting in ischemic damage to the retinal ganglion cells.

In our study, people with BMI of $30 \mathrm{~kg} / \mathrm{m}^{2}$ or greater were more likely to develop POAG than were those with BMI between 18.5 and $22.9 \mathrm{~kg} / \mathrm{m}^{2}$. In a subgroup analysis, this relationship was significant in those younger than 65 years of age and in women. Previous studies have noted that higher BMI was related with higher IOP, which is a major risk factor for POAG [30,31]. Cohen et al. [32] reported that obesity was an independent risk factor for elevated IOP. The Rotterdam Study separately reported that obesity was related with higher IOP [33]. The relationship between obesity and POAG, however, has not been established in a consistent manner. In a population-based study in the United States, Ko et al. [11] reported that BMI of $30 \mathrm{~kg} / \mathrm{m}^{2}$ or greater was significantly associated with prevalence of glaucoma. Elsewhere, Zang and Wynder [14] found that high BMI was associated with glaucoma. However, more studies have contrarily reported that prevalence of open-angle glaucoma was lower in the obese population $[9,12,13]$. The Barbados Eye Study also reported that those with high BMI showed decreased odds of open-angle glaucoma [12]. Nangia et al. [13] reported that lower BMI was related with higher prevalence of glaucoma based on a population study in Central India. In addition, Gasser et al. [34] reported that obesity was not a risk factor for glaucoma. These variations in results may be caused by different sociodemographic characteristics of the study populations, different definitions 
used to define metabolic syndrome or POAG, and different factors used to adjust for confounding effects. The association between BMI and POAG remains unclear, and further research is warranted.

Furthermore, in subgroup analyses, the relative risk effects and the effect of metabolic syndrome components assessed by absolute incidence increments were greater in younger subjects. Similar results were found in the Blue Mountains Eye Study, in which the association between DM and POAG was significant in the younger age group but not in the older age group ( $\geq 70$ years) [35]. The reason for this is unclear. Metabolic syndrome components may play a more important role in development of POAG in younger individuals. This may also be partly due to selection bias, indicating that younger subjects with metabolic syndrome components are more likely to visit an ophthalmologist than are those without [36].

We also compared the HR of developing POAG according to metabolic syndrome components and obesity status. Interestingly, those who were characterized as MUNO showed higher risk of developing POAG than those who were MHNO, but those who were $\mathrm{MHO}$ did not, indicating that metabolic status is more important than obesity. People who were MUNO were shown to exhibit impaired insulin sensitivity as well as higher BP, oxidative stress, abdominal adiposity, atherogenic lipid profile, risk of cardiovascular disease [37-39], and higher mortality compared with those who were MHO [17,40-42].

The strengths of this study are its large sample size representing nationwide data and the combination of medical claims data and health examination data. In addition, it is a prospective longitudinal cohort study that provides incidence and establishes the temporal sequence required for causal inference. Also, it provides graded associations between metabolic disease severity, obesity, and POAG.

When interpreting our data, the following should be taken into consideration. First, patients with POAG were identified based on ICD-10 codes; those who did not visit hospitals were not included in this study. In addition, no information about POAG severity or subtype was available, so we could not grade the associations between metabolic status, obesity, and POAG. Furthermore, other metabolic components such as waist circumference, high-density lipoprotein C, and triglyceride level could not be included in our analysis because they were not included in the health examination until 2009, when the National Health Insurance Service revised the health examination categories.
In conclusion, we found that metabolic health status significantly increased the risk of POAG in this prospective cohort from a nationwide database. This emphasizes the importance of glaucoma screening in patients with metabolic syndrome and obesity, including not only those who are MUO, but also those who are MUNO.

\section{CONFLICTS OF INTEREST}

No potential conflict of interest relevant to this article was reported.

\section{AUTHOR CONTRIBUTIONS}

Conception or design: Y.J., K.H.

Acquisition, analysis, or interpretation of data: Y.J., K.H., H. Y.L.P., S.H.L.

Drafting the work or revising: Y.J., S.H.L., C.K.P.

Final approval of the manuscript: Y.J., K.H., H.Y.L.P., S.H.L., C.K.P.

\section{ORCID}

Younhea Jung https://orcid.org/0000-0003-4223-0923

Chan Kee Park https://orcid.org/0000-0002-0922-8293

\section{ACKNOWLEDGMENTS}

The National Health Insurance Claims Database was provided by the National Health Insurance Sharing Service (NHISS) of Korea.

\section{REFERENCES}

1. Tham YC, Li X, Wong TY, Quigley HA, Aung T, Cheng CY. Global prevalence of glaucoma and projections of glaucoma burden through 2040: a systematic review and meta-analysis. Ophthalmology 2014;121:2081-90.

2. Sommer A, Tielsch JM, Katz J, Quigley HA, Gottsch JD, Javitt J, Singh K. Relationship between intraocular pressure and primary open angle glaucoma among white and black Americans. The Baltimore Eye Survey. Arch Ophthalmol 1991;109:1090-5.

3. Tielsch JM, Katz J, Sommer A, Quigley HA, Javitt JC. Family history and risk of primary open angle glaucoma. The Baltimore Eye Survey. Arch Ophthalmol 1994;112:69-73. 
4. Mitchell P, Smith W, Attebo K, Healey PR. Prevalence of openangle glaucoma in Australia. The Blue Mountains Eye Study. Ophthalmology 1996;103:1661-9.

5. Tielsch JM, Katz J, Singh K, Quigley HA, Gottsch JD, Javitt J, Sommer A. A population-based evaluation of glaucoma screening: the Baltimore Eye Survey. Am J Epidemiol 1991;134:110210.

6. Newman-Casey PA, Talwar N, Nan B, Musch DC, Stein JD. The relationship between components of metabolic syndrome and open-angle glaucoma. Ophthalmology 2011;118:1318-26.

7. Zheng Y, Wong TY, Mitchell P, Friedman DS, He M, Aung T. Distribution of ocular perfusion pressure and its relationship with open-angle glaucoma: the Singapore Malay Eye Study. Invest Ophthalmol Vis Sci 2010;51:3399-404.

8. Imai K, Hamaguchi M, Mori K, Takeda N, Fukui M, Kato T, Kawahito Y, Kinoshita S, Kojima T. Metabolic syndrome as a risk factor for high-ocular tension. Int J Obes (Lond) 2010;34: 1209-17.

9. Kim HA, Han K, Lee YA, Choi JA, Park YM. Differential association of metabolic risk factors with open angle glaucoma according to obesity in a Korean population. Sci Rep 2016;6: 38283.

10. Kim M, Jeoung JW, Park KH, Oh WH, Choi HJ, Kim DM. Metabolic syndrome as a risk factor in normal-tension glaucoma. Acta Ophthalmol 2014;92:e637-43.

11. Ko F, Boland MV, Gupta P, Gadkaree SK, Vitale S, Guallar E, Zhao D, Friedman DS. Diabetes, triglyceride levels, and other risk factors for glaucoma in the National Health and Nutrition Examination Survey 2005-2008. Invest Ophthalmol Vis Sci 2016;57:2152-7.

12. Leske MC, Connell AM, Wu SY, Hyman LG, Schachat AP. Risk factors for open-angle glaucoma. The Barbados Eye Study. Arch Ophthalmol 1995;113:918-24.

13. Nangia V, Jonas JB, Matin A, Bhojwani K, Sinha A, Kulkarni M, Gupta R, Khare A, Agarwal S, Bhate K, Nangia P, Nangia P, Panda-Jonas S. Prevalence and associated factors of glaucoma in rural central India. The Central India Eye and Medical Study. PLoS One 2013;8:e76434.

14. Zang EA, Wynder EL. The association between body mass index and the relative frequencies of diseases in a sample of hospitalized patients. Nutr Cancer 1994;21:247-61.

15. Karelis AD, Faraj M, Bastard JP, St-Pierre DH, Brochu M, Prud'homme D, Rabasa-Lhoret R. The metabolically healthy but obese individual presents a favorable inflammation profile. J Clin Endocrinol Metab 2005;90:4145-50.
16. Yang HK, Han K, Kwon HS, Park YM, Cho JH, Yoon KH, Kang MI, Cha BY, Lee SH. Obesity, metabolic health, and mortality in adults: a nationwide population-based study in Korea. Sci Rep 2016;6:30329.

17. Dvorak RV, DeNino WF, Ades PA, Poehlman ET. Phenotypic characteristics associated with insulin resistance in metabolically obese but normal-weight young women. Diabetes 1999; 48:2210-4.

18. Meigs JB, Wilson PW, Fox CS, Vasan RS, Nathan DM, Sullivan LM, D’Agostino RB. Body mass index, metabolic syndrome, and risk of type 2 diabetes or cardiovascular disease. J Clin Endocrinol Metab 2006;91:2906-12.

19. Teixeira TF, Alves RD, Moreira AP, Peluzio Mdo C. Main characteristics of metabolically obese normal weight and metabolically healthy obese phenotypes. Nutr Rev 2015;73:175-90.

20. Kwon S. Payment system reform for health care providers in Korea. Health Policy Plan 2003;18:84-92.

21. Oh SW, Lee S, Park C, Kim DJ. Elevated intraocular pressure is associated with insulin resistance and metabolic syndrome. Diabetes Metab Res Rev 2005;21:434-40.

22. Son J, Koh H, Son J. The association between intraocular pressure and different combination of metabolic syndrome components. BMC Ophthalmol 2016;16:76.

23. Bulpitt CJ, Hodes C, Everitt MG. Intraocular pressure and systemic blood pressure in the elderly. Br J Ophthalmol 1975;59: 717-20.

24. Sato T, Roy S. Effect of high glucose on fibronectin expression and cell proliferation in trabecular meshwork cells. Invest Ophthalmol Vis Sci 2002;43:170-5.

25. Zarei R, Anvari P, Eslami Y, Fakhraie G, Mohammadi M, Jamali A, Afarideh M, Ghajar A, Heydarzade S, Esteghamati A, Moghimi S. Retinal nerve fibre layer thickness is reduced in metabolic syndrome. Diabet Med 2017;34:1061-6.

26. Cho HK, Kee C. Population-based glaucoma prevalence studies in Asians. Surv Ophthalmol 2014;59:434-47.

27. Szaflik JP, Rusin P, Zaleska-Zmijewska A, Kowalski M, Majsterek I, Szaflik J. Reactive oxygen species promote localized DNA damage in glaucoma-iris tissues of elderly patients vulnerable to diabetic injury. Mutat Res 2010;697:19-23.

28. Flammer J, Mozaffarieh M. Autoregulation, a balancing act between supply and demand. Can J Ophthalmol 2008;43:317-21.

29. Lin HC, Chien CW, Hu CC, Ho JD. Comparison of comorbid conditions between open-angle glaucoma patients and a control cohort: a case-control study. Ophthalmology 2010;117:208895. 
30. Mori K, Ando F, Nomura H, Sato Y, Shimokata H. Relationship between intraocular pressure and obesity in Japan. Int J Epidemiol 2000;29:661-6.

31. Jonas JB, Nangia V, Matin A, Sinha A, Kulkarni M, Bhojwani K. Intraocular pressure and associated factors: the central India eye and medical study. J Glaucoma 2011;20:405-9.

32. Cohen E, Kramer M, Shochat T, Goldberg E, Garty M, Krause I. Relationship between body mass index and intraocular pressure in men and women: a population-based study. J Glaucoma 2016;25:e509-13.

33. Ramdas WD, Wolfs RC, Hofman A, de Jong PT, Vingerling JR, Jansonius NM. Lifestyle and risk of developing open-angle glaucoma: the Rotterdam study. Arch Ophthalmol 2011;129:767-72.

34. Gasser P, Stumpfig D, Schotzau A, Ackermann-Liebrich U, Flammer J. Body mass index in glaucoma. J Glaucoma 1999;8:811.

35. Mitchell P, Smith W, Chey T, Healey PR. Open-angle glaucoma and diabetes: the Blue Mountains eye study, Australia. Ophthalmology 1997;104:712-8.

36. Tielsch JM, Katz J, Quigley HA, Javitt JC, Sommer A. Diabetes, intraocular pressure, and primary open-angle glaucoma in the Baltimore Eye Survey. Ophthalmology 1995;102:48-53.

37. Kim M, Paik JK, Kang R, Kim SY, Lee SH, Lee JH. Increased oxidative stress in normal-weight postmenopausal women with metabolic syndrome compared with metabolically healthy overweight/obese individuals. Metabolism 2013;62:554-60.

38. Kwon BJ, Kim DW, Her SH, Kim DB, Jang SW, Cho EJ, Ihm SH, Kim HY, Youn HJ, Seung KB, Kim JH, Rho TH. Metabolically obese status with normal weight is associated with both the prevalence and severity of angiographic coronary artery disease. Metabolism 2013;62:952-60.

39. Choi KM, Cho HJ, Choi HY, Yang SJ, Yoo HJ, Seo JA, Kim SG, Baik SH, Choi DS, Kim NH. Higher mortality in metabolically obese normal-weight people than in metabolically healthy obese subjects in elderly Koreans. Clin Endocrinol (Oxf) 2013; 79:364-70.

40. Conus F, Allison DB, Rabasa-Lhoret R, St-Onge M, St-Pierre DH, Tremblay-Lebeau A, Poehlman ET. Metabolic and behavioral characteristics of metabolically obese but normal-weight women. J Clin Endocrinol Metab 2004;89:5013-20.

41. Lee SH, Ha HS, Park YJ, Lee JH, Yim HW, Yoon KH, Kang MI, Lee WC, Son HY, Park YM, Kwon HS. Identifying metabolically obese but normal-weight (MONW) individuals in a nondiabetic Korean population: the Chungju Metabolic disease Cohort (CMC) study. Clin Endocrinol (Oxf) 2011;75:475-81.

42. Lee SH, Han K, Yang HK, Kim HS, Cho JH, Kwon HS, Park YM, Cha BY, Yoon KH. A novel criterion for identifying metabolically obese but normal weight individuals using the product of triglycerides and glucose. Nutr Diabetes 2015;5:e149. 